\title{
STUDY ON FACTORS AFFECTING BIM IMPLEMENTATION IN EUROPEAN RENOVATION PROJECTS
}

\author{
FATEMEH DANESHVARTARIGH ${ }^{1,2, *} \&$ SERGIO ROSSI ${ }^{1}$ \\ ${ }^{1}$ Metropolia University of Applied Sciences, Finland \\ ${ }^{2}$ HTW Berlin University of Applied Sciences, Germany
}

\begin{abstract}
New technologies and applications have radically altered construction techniques in recent years. In order to anticipate how the building will act, perform, and appear, these technologies encompass a wide range of visualization, simulation, and analytic tools. These new technologies and applications have a considerable impact on completing construction projects in today's AEC industries. The rate of changes in BIM-related topics is different worldwide, and it depends on many factors, e.g., the national policies of each country. Therefore, there is a need for comprehensive research focused on a specific area with common characteristics. One of the necessary measures to increase the use of this new approach is to examine the challenges and obstacles facing it. In this research, based on the Delphi method, at first, the background and related literature are reviewed. Then, using the knowledge obtained from the literature, a primary questionnaire is generated and filled by experts who are selected using snowball sampling. It covered the experts' attitudes towards implementing BIM in renovation projects and their view of the benefits and obstacles in this regard. By analyzing the primary questionnaire, the second group of experts is selected among the participants to be interviewed. The results are analyzed using Theme analysis. Six themes, including Management support, Staff resistance, Client willingness, Cost of software and implementation, the difficulty of implementation, and other reasons, are obtained. Then a final questionnaire is generated from the themes and filled by the same group of experts. The result is analyzed by the Fuzzy Delphi method, showing the exact ranking of the obtained themes. The final results show that Management support, Staff resistance, and Client willingness are the most critical barrier to BIM usage in renovation projects.
\end{abstract}

Keywords: building information modeling, BIM, BIM implementation, BIM barriers, BIM in renovation.

\section{INTRODUCTION}

Nowadays, the construction industry, like other industries, has undergone many growths and transformations, which has caused it to be divided into various categories. From residential to commercial or industrial areas, all have experienced fundamental changes. Construction trends in recent years show that intelligence, productivity, and profitability are the main factors that are improved. Understanding the developments in the construction industry and recognizing solutions to overcome business barriers will help construction companies to scale their company effectively for the upcoming decades.

New technologies and applications have radically altered construction techniques in recent years. In order to anticipate how the building will act, perform, and appear, these technologies encompass a wide range of visualization, simulation, and analytic tools. These new technologies and applications have a considerable impact on completing construction projects in today's architectural, engineering, and construction industries.

*ORCID: https://orcid.org/0000-0003-2963-427X 
Business owners, contractors, consultants, architects, engineers, and subcontractors use communication platforms to standardize business procedures to manage and exchange information.

Building information modeling is a digital depiction of a facility's physical and functional characteristics and a shared database for information about decisions made throughout its life cycle [1]. Simulating and analyzing the structure with the aid of modern modeling technologies allows project stakeholders to see how a building behaves, how it will function, or how it will look far more realistic than ever before.

However, it is critical to determine the shareholders' duties, the range of information to be exchanged in the project, and the supporting software utilized in the construction execution procedures. To summarize, the technology and use of BIM Systems, aid in the completion of building projects in less time, at a lower cost, and in a more sustainable manner.

\section{LITERATURE REVIEW}

According to Gökgür's research findings in 2015 [2], the potential benefits of BIM for new construction are widely recognized by experts. However, there are still hurdles such as low client demand, the complexity of renovation projects, and a shortage of qualified labor to adopt BIM for renovation projects. The study's findings emphasize the potential for increased and improved BIM utilization in future renovation projects.

An extensive literature review in 2017 carried out by Joblot et al. found out that few scholarly references are devoted to this issue, highlighting that the renovation sector is not a key target of BIM publications (less than $2 \%$ specifically addressed renovation). It stated that the current technology and tools, which are sometimes quite expensive, have not shown their profitability for this business type.

It confirms the conclusions of Ilter and Ergen [3] that obtained about five results among 500 articles by querying other databases with these same research topics. It shows that nearly $60 \%$ of the publications focused on energy optimization, and there is a very fair coverage of the entire scope defined. Finally, it suggested that it is necessary to map the different observable renovation processes and highlights some gaps that need future works [4].

Based on the review of previous works, most of the efforts have focused either on case studies where BIM is implemented in renovation projects or the development of BIM tools. Previously, the research is conducted by focusing on the specific individual benefits of using BIM in a renovation project; however, the overall and actual percentage of BIM use in renovation companies has not been studied yet. Based on the current situation of renovation projects and focusing on a specific market, analyzing the experts' ideas about the applicability of BIM in renovation projects seems essential. And due to the rapid advancement in BIM technologies, there is a need for continued research to clear the path for future improvements in this area.

\section{METHODOLOGY}

The study's goal is to conduct an exploratory investigation. The research philosophy is pragmatism because it focuses on current practical issues. It has a deductive approach, and it follows the grounded theory strategy. The research enjoys Multiple-methods where qualitative and quantitative data collection methods are used. Snowball sampling is used to acquire data. The research is a cross-sectional study in terms of time horizons. The overall research method is based on the Delphi method, and the data analysis is performed by the Fuzzy Delphi method. 


\section{ANALYSIS OF THE RESULT}

The main barriers and factors affecting incorporating BIM in renovation projects are identified by using the Delphi method. This method includes a basic questionnaire, an interview, and a final questionnaire.

\subsection{The first questionnaire}

In this section, the authors found the main barriers and factors affecting incorporating BIM in renovation projects. Using the Delphi method, a basic questionnaire is generated to collect general information about the research. The first questionnaire is designed and conducted through the online software tool SurveyMonkey ${ }^{\mathrm{TM}}$. The scope of research is limited to northern and western Europe. The questions are in accordance with the checklist of questions for designing a survey method by Cresswell [5]. It is filled by seventy-four experts whose education and jobs are related to BIM, and results are collected out of the questionnaire. A primary conclusion obtained from the first questionnaire shows the general opinions of the participants about the barriers. The validity and reliability of the questionnaire are checked by using Cronbach's alpha formula shown in eqn (1). The calculated value is 0.87 and according to Table 1 , the internal consistency of the questionnaires is good.

$$
\alpha=\frac{k}{k-1}\left(1-\frac{\left.\sum_{i=1}^{k} \sigma_{y_{i}}^{2}\right)}{\sigma^{2} x}\right) .
$$

Table 1: Acceptable Cronbach's alpha test of reliability range (in conformity with [6]).

\begin{tabular}{|c|c|}
\hline $\begin{array}{c}\text { Cronbach's alpha } \\
\text { coefficients }\end{array}$ & $\begin{array}{c}\text { Internal } \\
\text { consistency }\end{array}$ \\
\hline $\boldsymbol{\alpha} \geq \mathbf{0 . 9}$ & Excellent \\
\hline $\mathbf{0 . 9}>\boldsymbol{\alpha} \geq \mathbf{0 . 8}$ & Good \\
\hline $\mathbf{0 . 8}>\boldsymbol{\alpha} \geq \mathbf{0 . 7}$ & Acceptable \\
\hline $\mathbf{0 . 7}>\boldsymbol{\alpha} \geq \mathbf{0 . 6}$ & Questionable \\
\hline $\mathbf{0 . 6}>\boldsymbol{\alpha} \geq \mathbf{0 . 5}$ & Poor \\
\hline $\mathbf{0 . 5}>\boldsymbol{\alpha}$ & Unacceptable \\
\hline
\end{tabular}

\subsection{The interview}

After analyzing the first questionnaire and as a qualitative part of the research, according to the derived data, interviews are performed with 18 experts selected according to their relevant education/experience among the questionnaire's initial respondents.

The interview findings were classified and open coded using theme analysis suggested by Corbin [7] for Grounded Theory research. Open coding is an analytical procedure through which concepts are identified and their properties and dimensions are discovered. At this stage, Grounded Theory forms the primary categories of information about the phenomenon under study by segmenting the information. The researcher then classifies the collected data based on their categories. The classified data forms the themes. The researcher considers meaningful patterns and topics related to the research. This analysis involves a continuous flow between data sets and chosen patterns, and finally, related patterns are extracted and coded. The researcher, using theme analyses, extracted 34 basic open codes out of interviews along with their frequencies, which are mentioned in Table 2. 
Table 2: Basic concepts and open codes of interviews.

\begin{tabular}{|l|l|l|}
\hline \multirow{2}{*}{ Open code } & Basic concepts & \multicolumn{2}{|c|}{$\begin{array}{l}\text { Frequency } \\
\text { at interview }\end{array}$} \\
\hline A1 & Lack of knowledge of managers & 8 \\
\hline A2 & Management support & 5 \\
\hline A3 & High cost of software & 6 \\
\hline A4 & Insufficient understanding of the benefits & 5 \\
\hline A5 & Use of traditional method & 7 \\
\hline A6 & Complexity & 9 \\
\hline A7 & Not being demanded by the clients & 7 \\
\hline A8 & Management attitude & 6 \\
\hline A9 & ICT Implementation problem & 3 \\
\hline A10 & Most of staffs are old and not willing to use systems & 4 \\
\hline A11 & Lack of expertise & 8 \\
\hline A12 & High costs & 5 \\
\hline A13 & Fear of failure & 3 \\
\hline A14 & Projects are too small to use BIM & 7 \\
\hline A15 & High cost of implementation & 5 \\
\hline A16 & Lack of relevant software & 3 \\
\hline A17 & Decision makers don't provide full support & 2 \\
\hline A18 & Legal barriers exit & 6 \\
\hline A19 & Unavailability of proper training on BIM & 8 \\
\hline A20 & Lack of long-term thinking & 8 \\
\hline A21 & Resistance to change & 8 \\
\hline A22 & End-user does not realize the benefits & 3 \\
\hline A23 & Lack of guidelines and standards & 5 \\
\hline A24 & Hard to implement in renovation projects & 4 \\
\hline A25 & Only being hired for the first phases & 8 \\
\hline A26 & Employee's avoidance of changing their way of working & 7 \\
\hline A27 & Cost of new software & 7 \\
\hline A28 & Cost of updating the system & 7 \\
\hline A29 & Cost of training the team & 9 \\
\hline A30 & Lack of experience in BIM projects & 8 \\
\hline A31 & Lack of collaboration & 5 \\
\hline A32 & BIM licensing & 4 \\
\hline A33 & Maintenance costs & \\
\hline A34 & Lack of BIM risk insurances & \\
\hline & & \\
\hline
\end{tabular}

Next step, the researcher identifies potential themes to be aggregated. In other words, it must be decided which first-level code has a proper semantic relationship with others to be placed in a category or theme. Table 3 shows part of the extracted main and sub themes. 
Table 3: Part of extracted main and sub themes.

\begin{tabular}{|c|c|c|c|c|c|c|}
\hline ठृ & 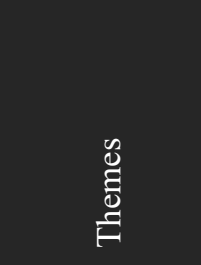 & 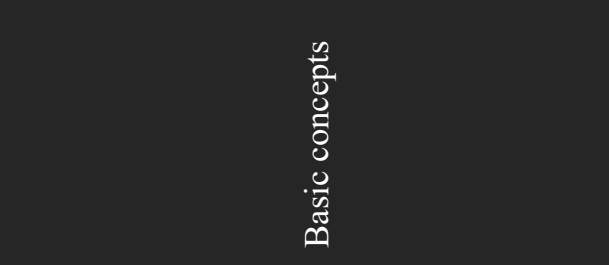 & 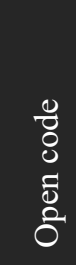 & 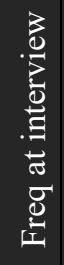 & 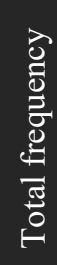 & 亲 \\
\hline \multirow{5}{*}{ B1 } & \multirow{5}{*}{$\begin{array}{l}\text { Management } \\
\text { support }\end{array}$} & Lack of knowledge of managers & A1 & 9 & \multirow{5}{*}{43} & \multirow{5}{*}{1} \\
\hline & & Management support & $\mathrm{A} 2$ & 10 & & \\
\hline & & Management attitude & $\mathrm{A} 8$ & 8 & & \\
\hline & & Decision makers don't provide full support & A17 & 8 & & \\
\hline & & Lack of long-term thinking & A20 & 8 & & \\
\hline \multirow{9}{*}{ B2 } & \multirow{9}{*}{ High cost } & High cost of software & A3 & 3 & \multirow{9}{*}{27} & \multirow{9}{*}{4} \\
\hline & & High Costs & A12 & 2 & & \\
\hline & & High cost of implementation & A15 & 3 & & \\
\hline & & Cost of new software & $\mathrm{A} 27$ & 3 & & \\
\hline & & Cost of updating the system & A28 & 4 & & \\
\hline & & Cost of training the team & A29 & 3 & & \\
\hline & & BIM licensing & A32 & 3 & & \\
\hline & & Lack of relevant software & A16 & 3 & & \\
\hline & & Maintenance costs & A33 & 3 & & \\
\hline
\end{tabular}

4.3 Final questionnaire

To finalize the research finding, the final themes, which are the results of the interviews, are used to create the final questionnaire having a Five-Point Likert Scale based on Delphi's approach. The ranges of the answers are from strongly agree to strongly disagree. Output of the final questionnaire is summarized in Table 4.

Finally, the extracted scores are converted to the TFN using the Fuzzy Delphi method. This process enabled the authors to get the exact impact of each barrier and better understand the qualitative data of linguistic ideas of experts. The conversion of five-point Likert Scale to Triangular Fuzzy Numbers [8] are summarized in Table 5.

The associated membership function is calculated by eqn (2) [9], in which $l \leq m \leq u$ and where $l, m$ and $u$ are real numbers. Therefore, TFN number $w_{i j}$ is TFN of expert $i$ for question $j$.

$$
\mu_{\bar{N}}(x)=\left\{\begin{array}{c}
0, x<1 \\
\frac{(x-1)}{(m-1)}, 1 \leq x \leq m, \\
\frac{(u-x)}{(u-m)}, m \leq x \leq u, \\
0, x>u,
\end{array} .\right.
$$

Finally, the generated TFN is stored in a table. A sample of generated TFN for four experts is presented in Table 6. As it is shown in the table, there are three $\mathrm{L}, \mathrm{M}$, and $\mathrm{U}$ numbers for each answer of every expert. 
Table 4: Output of the final questionnaire.

\begin{tabular}{|c|c|c|c|c|c|c|c|}
\hline $\begin{array}{l}\frac{n}{0} \\
\frac{0}{0} \\
\frac{2}{x} \\
\text { II }\end{array}$ & 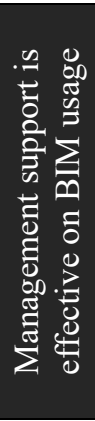 & 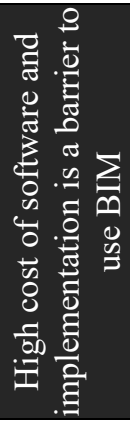 & 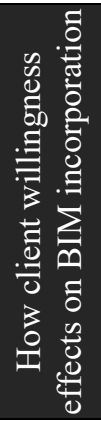 & 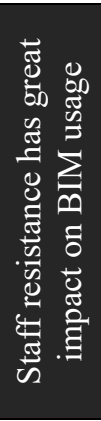 & 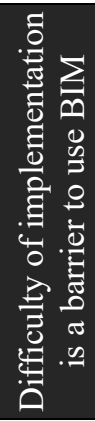 & 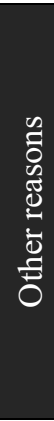 & 푬 \\
\hline Expert1 & 4 & 3 & 3 & 5 & 3 & 1 & 19 \\
\hline Expert2 & 5 & 5 & 4 & 3 & 1 & 1 & 19 \\
\hline Expert3 & 3 & 4 & 4 & 4 & 2 & 2 & 19 \\
\hline Expert4 & 5 & 2 & 3 & 4 & 4 & 2 & 20 \\
\hline Expert5 & 4 & 3 & 4 & 5 & 2 & 3 & 21 \\
\hline Expert6 & 5 & 3 & 4 & 3 & 3 & 2 & 20 \\
\hline Expert7 & 2 & 4 & 5 & 4 & 2 & 2 & 19 \\
\hline Expert8 & 4 & 2 & 2 & 5 & 4 & 3 & 20 \\
\hline Expert9 & 3 & 5 & 4 & 5 & 3 & 2 & 22 \\
\hline Expert10 & 2 & 4 & 3 & 4 & 3 & 4 & 20 \\
\hline Expert11 & 5 & 2 & 4 & 4 & 2 & 3 & 20 \\
\hline Expert12 & 5 & 3 & 4 & 3 & 4 & 3 & 22 \\
\hline Expert13 & 5 & 4 & 5 & 4 & 3 & 4 & 25 \\
\hline Expert14 & 4 & 3 & 5 & 4 & 3 & 4 & 23 \\
\hline Expert15 & 3 & 4 & 4 & 1 & 2 & 3 & 17 \\
\hline Expert16 & 4 & 3 & 2 & 4 & 4 & 2 & 19 \\
\hline Expert17 & 4 & 5 & 2 & 3 & 4 & 2 & 20 \\
\hline Expert18 & 4 & 2 & 3 & 5 & 3 & 2 & 19 \\
\hline
\end{tabular}

Table 5: Triangular fuzzy numbers for five-point scale.

\begin{tabular}{|l|c|c|c|c|c|}
\hline \multicolumn{7}{|c|}{ Likert scale } \\
\hline Linguistic terms & $\begin{array}{c}\text { Strongly } \\
\text { disagree }\end{array}$ & Disagree & $\begin{array}{c}\text { Neither } \\
\text { agree nor } \\
\text { disagree }\end{array}$ & Agree & $\begin{array}{c}\text { Strongly } \\
\text { agree }\end{array}$ \\
\hline Linguistic value & 1 & 2 & 3 & 4 & 5 \\
\hline TFN & $0.0,0.0,0.2$ & $0.0,0.2,0.4$ & $0.20,0.4,0.60$ & $0.4,0.6,0.8$ & $0.60,0.8,1.00$ \\
\hline
\end{tabular}

After fuzzification and experts' opinions aggregation, to get understandable numbers, the resulted values should be defuzzified. The defuzzifier receives the fuzzy input and converts it to the crisp output. There are several methods for defuzzification. The authors selected the one mentioned in eqn (3), which is one of the suggested methods in qualitative research [10]. 
Table 6: Score of 4 experts converted to TFN (as an example).

\begin{tabular}{|c|c|c|c|c|c|c|c|c|c|c|c|}
\hline \multicolumn{3}{|c|}{ Expert 1 } & \multicolumn{3}{c|}{ Expert 2 } & \multicolumn{3}{c|}{ Expert 3 } & \multicolumn{3}{c|}{ Expert 4 } \\
\hline $\mathrm{L}$ & $\mathrm{M}$ & $\mathrm{U}$ & $\mathrm{L}$ & $\mathrm{M}$ & $\mathrm{U}$ & $\mathrm{L}$ & $\mathrm{M}$ & $\mathrm{U}$ & $\mathrm{L}$ & $\mathrm{M}$ & $\mathrm{U}$ \\
\hline 0.40 & 0.60 & 0.80 & 0.60 & 0.80 & 1.00 & 0.20 & 0.40 & 0.60 & 0.60 & 0.80 & 1.00 \\
\hline 0.20 & 0.40 & 0.60 & 0.60 & 0.80 & 1.00 & 0.40 & 0.60 & 0.80 & 0.00 & 0.20 & 0.40 \\
\hline 0.20 & 0.40 & 0.60 & 0.40 & 0.60 & 0.80 & 0.40 & 0.60 & 0.80 & 0.20 & 0.40 & 0.60 \\
\hline 0.60 & 0.80 & 1.00 & 0.20 & 0.40 & 0.60 & 0.40 & 0.60 & 0.80 & 0.40 & 0.60 & 0.80 \\
\hline 0.20 & 0.40 & 0.60 & 0.00 & 0.00 & 0.20 & 0.00 & 0.20 & 0.40 & 0.40 & 0.60 & 0.80 \\
\hline 0.00 & 0.00 & 0.20 & 0.00 & 0.00 & 0.20 & 0.00 & 0.20 & 0.40 & 0.00 & 0.20 & 0.40 \\
\hline
\end{tabular}

Table 7: Result of defuzzification (crisp scores).

\begin{tabular}{|c|c|c|c|c|c|c|}
\hline \# & Questions & $\mathrm{L}$ & M & $\mathrm{U}$ & Fuzzy average & Rank \\
\hline 1 & $\begin{array}{l}\text { Management support is effective on BIM } \\
\text { usage }\end{array}$ & 7 & 21 & 14 & 1.76 & 1 \\
\hline 2 & $\begin{array}{l}\text { High cost of software and implementation } \\
\text { is a barrier to use BIM }\end{array}$ & 5 & 17 & 12 & 1.40 & 4 \\
\hline 3 & $\begin{array}{l}\text { How client willingness effects on BIM } \\
\text { incorporation }\end{array}$ & 6 & 19 & 13 & 1.55 & 3 \\
\hline 4 & $\begin{array}{l}\text { Staff resistance has great impact on BIM } \\
\text { usage }\end{array}$ & 7 & 21 & 14 & 1.74 & 2 \\
\hline 5 & $\begin{array}{l}\text { Difficulty of implementation is a barrier to } \\
\text { use BIM }\end{array}$ & 3 & 14 & 10 & 1.09 & 5 \\
\hline 6 & Other reasons & 2 & 11 & 9 & 0.85 & 6 \\
\hline
\end{tabular}

The results of defuzzification using the defuzzifier is mentioned in Table 7.

As shown in the table, management support has a 1.76 fuzzy average score and stands as the first rank. Staff resistance with 1.74 scores is the second barrier, client willingness has a 1.55 score and stands as the third, and high cost of software and implementation with 1.4 Fuzzy average scores is the fourth barrier from the point of view of the experts. The fifth one in the table belongs to the Difficulty of implementation that has a 1.09 fuzzy average. Other reason is the last one with 0.85 fuzzy average scores.

\section{CONCLUSION}

In this paper using the Delphi method, a basic questionnaire filled by 74 BIM experts, collected some general information related to the research. Then, the interviews with 18 selected experts are analyzed by theme analysis method, 34 open codes are extracted, and six themes are created. In order to get the exact weight of the selected themes and according to the Delphi method, the final questionnaire created from the extracted themes, is sent to the same 18 experts. As a result, the detected barriers are management support, staff resistance, client willingness, high cost of software and implementation, difficulty of implementation, and other reason respectively. Finally, the extracted scores are converted to the triangular fuzzy numbers using the Fuzzy Delphi method. This enabled the authors to get the exact impact of each barrier and better understand the qualitative data of linguistic 
ideas of experts. Then the obtained TFNs are defuzzificated and the Fuzzy average and rank of each theme are calculated. The interesting point is that the output of two calculations of classic and Fuzzy Delphi are identical.

\section{REFERENCES}

[1] Jensen, P.A. \& Maslesa, E., Value based building renovation - A tool for decisionmaking and evaluation. Building and Environment, 92, pp. 1-9, 2015.

[2] Gökgür, A., Current and future use of BIM in renovation projects, 2015.

[3] Ilter, D. \& Ergen, E., BIM for building refurbishment and maintenance: Current status and research directions. Structural Survey, 33(3), pp. 228-256, 2015.

[4] Joblot, L., Paviot, T., Deneux, D. \& Lamouri, S., Literature review of building information modeling (BIM) intended for the purpose of renovation projects. IFACPapersOnLine, 50(1), pp. 10518-10525, 2017.

[5] Creswell, J.W., Research Design: Qualitative, Quantitative, and Mixed Methods Approaches, 4th ed., SAGE Publications: Thousand Oaks, 2014.

[6] Cronbach, L.J., Coefficient alpha and the internal structure of tests. Psychometrika, 16(3), pp. 297-334, 1951.

[7] Corbin, J., Basics of Qualitative Research: Techniques and Procedures for Developing Grounded Theory, 4th ed., SAGE Publications: New York, 2014.

[8] Cheng, C., Group opinion aggregation based on a grading process: A method for constructing triangular fuzzy numbers. Computers \& Mathematics with Applications, 48(10-11), pp. 1619-1632, 2004.

[9] Shahyamal, A.K. \& Pal, M., Triangular fuzzy matrices. Iranian Journal of Fuzzy Systems, 4(1), pp. 75-87, 2007.

[10] Talon, A. \& Curt, C., Selection of appropriate defuzzification methods: Application to the assessment of dam performance. Expert Systems with Applications, 70, pp. 160-174, 2017. 